Original article

Section: Food Technology

\title{
Development of New Gluten-Free Maize-Field Bean Bread Dough: Relationships Between Rheological Properties and Structure of Non-Gluten Proteins
}

\author{
Awatif Fetouhi ${ }^{1}$, Agnieszka Sujak ${ }^{2 *} \oplus$, Leila Bentallah ${ }^{1}$, Agnieszka Nawrocka ${ }^{3}$, \\ Monika Szymańska-Chargot ${ }^{4}$, Marta Tomczyńska-Mleko ${ }^{5}{ }^{\circledR}$, \\ Agnieszka Wójtowicz ${ }^{6}{ }^{\circledR}$, Mohammed Nasreddine Zidoune $^{1}$ \\ 'Institut de la Nutrition, de l'Alimentation et des Technologies Agro-Alimentaires, \\ Université des Frères Mentouri, Constantine 1, Route de Ain El_Bey, Constantine, Algeria \\ ${ }^{2}$ Department of Biosystems Engineering, Faculty of Environmental and Mechanical Engineering, \\ Poznań University of Life Sciences, Wojska Polskiego 50, 60-637 Poznań, Poland \\ ${ }^{3}$ Laboratory for Quality Assessment of Grain and Oilseed Raw Materials, Institute of Agrophysics, \\ Polish Academy of Sciences, Doświadczalna 4, 20-290 Lublin, Poland \\ ${ }^{4}$ Department of Microstructure and Mechanics of Biomaterials, Institute of Agrophysics, \\ Polish Academy of Sciences, Doświadczalna 4, 20-290 Lublin, Poland \\ Institute of Plant Genetics, Breeding and Biotechnology, \\ University of Life Sciences in Lublin, Akademicka 15, 20-950 Lublin, Poland \\ ${ }^{6}$ Department of Thermal Technology and Food Process Engineering, \\ University of Life Sciences, Gtęboka 31, 20-612 Lublin, Poland
}

Key words: gluten-free dough, maize, field bean, non-gluten proteins, pasting properties, protein secondary structure, FT-Raman spectroscopy

This work aimed to examine the rheological properties and structural features of newly developed gluten-free doughs with maize (M), field bean (FB), maize-filed bean (MFB), and maize-field bean improved with hydrothermally-treated maize (IMFB), and compare them with soft wheat (SW) dough as a control. The relationships between viscoelastic characteristics, pasting properties of dough, and structure of non-gluten proteins analyzed using FT-Raman spectroscopy were investigated. All gluten-free doughs showed significantly higher values of the elastic modulus than SW dough. The low values of $\tan \delta$ for doughs of M, MFB, and IMFB formulas indicated strong contribution of the solid character in their structural formation as compared to SW and FB doughs. Protein backbone of maize and maize-based doughs was characterized by the absence of pseudo- $\beta$-sheet structure and a high content of $\beta$-sheet accompanied with a low content of antiparallel- $\beta$-sheet. According to principal component analysis (PCA), a strong relationship was found between protein secondary structure, $\tan \delta$, gelatinization temperature, and between aromatic amino-acid chains, peak viscosity, and breakdown. The mechanism of non-gluten protein network establishment was based on the formation of $\beta$-sheet and $\alpha$-helix structure. The study results indicate the significant involvement of trans-gauche-gauche (TGG) and trans-gauche-trans (TGT) disulfide bridges in the formation of the non-gluten protein matrix rather that gauche-gauche-gauche $(\mathrm{GGG})$ conformation. PCA analysis showed that the water absorption of the starch granules increased with the greater exposition of the tyrosyl residues.

\section{INTRODUCTION}

Obtaining gluten-free bread (GFB) of superior quality is a technological challenge. Gluten is considered as a key component imparting wheat dough its unique properties in baked goods. It is composed of gliadins and glutenins - two proteins that contribute to the bread dough viscosity and elasticity [Barak et al., 2014; Belton, 1999]. According to Singh \& MacRitchie [2001], gluten structure develops and becomes apparent when the wheat flour is hydrated and subjected to the energy of mixing.
It is defined as a viscoelastic mass capable of forming structures that retain gases allowing dough to expand and become soft, light, and palatable after baking [Khatkar \& Schofield, 2007].

The inability of gluten-free (GF) flour to form viscoelastic dough after kneading with water, makes production of GFB technologically difficult. The study of the mechanisms of development of the structure of gluten-free bread dough with or without improvement is thus the key to the understanding and controlling the functionality of components, and it brings up possible solutions to improve GF product quality.

\footnotetext{
* Corresponding Author:

agnieszka.sujak@up.poznan.pl (A. Sujak)
} 
FT-IR and FT-Raman spectroscopy has been used in several studies to determine the dough structure development and to investigate the gluten-protein quality and structure relationships [Nawrocka et al., 2016b; Pourfarzad et al., 2015; Sivam et al., 2013; Wang et al., 2015]. Our recent study [Fetouhi et al., 2019] on the viscoelastic behavior of rice-field bean gluten-free dough using FT-IR concluded that the low viscoelastic quality of this type of GF dough is due to the different secondary structures developed by non-gluten as compared to gluten proteins. Accordingly, in non-gluten proteins, $\beta$-sheet content increased, albeit with the absence of $\beta$-turn structures. The reorganization of starch molecules also had an effect on the quality of GFB doughs. Moreover, a relationship between the structure of proteins and starch and the viscoelastic behavior of rice-field bean dough was clearly indicated. As rice and rice-field bean preparations showed low kneading quality, we started to search for other formulas.

In this context, our work aimed to study the structural features of newly developed types of GF dough based on maize-field bean formulas through examining correlations between rheological properties and structure of non-gluten proteins. Maize (M) and field bean (FB) flours were chosen in order to obtain a balanced composition of blended amino acid in GF bread. As the conformation of the S-S bridges plays a major role in the functional properties of gluten dough, the disulfide bridge regions were analyzed in GF doughs and compared with soft wheat dough. FT-Raman spectroscopy has not yet been adapted in GF dough investigation to identify the relationship between structural mechanisms and quality of GF bread dough development.

\section{MATERIALS AND METHODS}

\section{Raw materials}

Soft wheat (SW) flour (Triticum aestivum) (Młyn Piaski, Piaski, Poland) was purchased locally. Maize (Zea mays L.) (Alicampo Company, Del Viso, Buenos Aires, Argentina) and field bean (Vicia faba L.) (Al-behera, Tanta, Egypt) seeds were purchased from the Algerian market. The seeds were ground using an MG E3 grinder (UMA Rouiba, Ar_Ruwajba, Algeria) and sieved to obtain flours with a particle size less than $200 \mu \mathrm{m}$. Sodium chloride was purchased from Sigma Aldrich (Poznań, Poland). Distilled water was used for dough preparation (Hydrolab, Straszyn, Poland). The chemical composition of raw materials was evaluated according to American Association of Cereal Chemists (AACC) [1995] methods: AACC 46-10 for protein, AACC 30-10 for fat, and AACC 08-01 for ash content. Total dietary fiber was determined based on the Association of Official Analytical Chemists (AOAC) 993.21 procedure [AOAC, 2000]. Proximate composition of raw materials was: $\mathrm{SW}$ - protein $12.25 \mathrm{~g} / 100 \mathrm{~g}$, fat $0.98 \mathrm{~g} / 100 \mathrm{~g}$, ash $0.55 \mathrm{~g} / 100 \mathrm{~g}$, dietary fiber $1.30 \mathrm{~g} / 100 \mathrm{~g}$; $\mathrm{M}$ - protein $5.13 \mathrm{~g} / 100 \mathrm{~g}$, fat $1.41 \mathrm{~g} / 100 \mathrm{~g}$, ash $0.45 \mathrm{~g} / 100 \mathrm{~g}$, dietary fiber $2.00 \mathrm{~g} / 100 \mathrm{~g}$; and $\mathrm{FB}$ - protein $23.91 \mathrm{~g} / 100 \mathrm{~g}$, fat $3.91 \mathrm{~g} / 100 \mathrm{~g}$, ash $7.82 \mathrm{~g} / 100 \mathrm{~g}$, dietary fiber $9.33 \mathrm{~g} / 100 \mathrm{~g}$.

\section{Dough preparation}

All tested doughs were prepared using a Farinograph-E (model 81101142, Brabender, Germany) equipped with a $50 \mathrm{~g}$ mixer. Here, $50 \mathrm{~g}$ of SW or gluten-free flours (M, FB, and maize-field bean (MFB) formula) and aqueous solution of sodium chloride $(2 \%, w / w)$ were kneaded for 20 min with an appropriate amount of distilled water determined according to the Farinograph optimal conditions (500 FU). MFB formula was obtained by mixing $33.34 \%$ of FB flour with $66.66 \%$ of $\mathrm{M}$ flour in order to obtain a balanced composition of blended amino acids [Benatallah et al., 2012]. An improved maize-field bean (IMFB) formula was prepared according to the procedure described by Bourekoua et al. [2016], where a portion of $6.9 \mathrm{~g}$ of maize flour was mixed with $34.5 \mathrm{~mL}$ of distilled water and heated to $65^{\circ} \mathrm{C}$ with continuous stirring. The obtained gel was stored at $4^{\circ} \mathrm{C}$ for $24 \mathrm{~h}$ and then added to a mixture of $16.67 \mathrm{~g}$ of field bean and $26.43 \mathrm{~g}$ of maize flours. Water amounts added to each sample, as well as dough water absorption (WA) are presented in Table 1. All doughs were allowed to rest for $20 \mathrm{~min}$ at room temperature before oscillatory tests. Samples for FT-Raman analysis and pasting proprieties determination were lyophilized for $24 \mathrm{~h}(0.04 \mathrm{mbar}$, $\left.-50^{\circ} \mathrm{C}\right)$. After freeze-drying, they were ground to powder in a laboratory grinder (MK100S, Katowice, Poland).

\section{Rheological proprieties}

\section{Small strain oscillatory test}

The oscillatory test was done to estimate the differences in the viscoelastic behavior of non-gluten doughs in comparison with control SW dough. The measurements were conducted using a Rheo-Stress 300 rheometer (Karlsruhe, Germany) equipped with parallel plates of $5 \mathrm{~cm}$ in diameter with the adjusted gap of $2 \mathrm{~mm}$. After the resting time (20 min), dough was placed between the plates, the excess of dough was removed, and it was then subjected to scanning at $20^{\circ} \mathrm{C}$ with a frequency sweep ranging between $0.1-10 \mathrm{~Hz}$ and low strain value $(0.1 \%)$ in order to keep the examined dough in a linear viscoelastic region determined via strain sweep tests performed at $1 \mathrm{~Hz}$ frequency according to Lazaridou et al. [2007]. The storage (G') modulus, loss (G”) modulus, and the loss tangent $(\tan \delta$ ) were recorded. For each type of dough, the test was done in duplicate.

\section{Pasting properties}

Measurements were performed according to Dib et al. [2018], using a microvisco-amylograph (Brabender OHG, Duisburg, Germany) operated under constant conditions of speed $(250 \mathrm{rpm})$ and sensitivity $(235 \mathrm{~cm} \times \mathrm{g})$. Freeze-dried dough powders $(10 \mathrm{~g})$ and an appropriate amount of distilled water (corrected to compensate of $14 \%$ moisture) were mixed and continuously stirred for 5 min to obtain a homogeneous dispersion. The sample was heated from $30^{\circ} \mathrm{C}$ up to $93^{\circ} \mathrm{C}$, held at $93^{\circ} \mathrm{C}$ for $5 \mathrm{~min}$, cooled from $93^{\circ} \mathrm{C}$ to $50^{\circ} \mathrm{C}$, and held at $50^{\circ} \mathrm{C}$ for $1 \mathrm{~min}$. The heating/cooling rate was $7.5^{\circ} \mathrm{C} / \mathrm{min}$. The estimated proprieties were: gelatinization temperature (GT, $\left.{ }^{\circ} \mathrm{C}\right)$, initial viscosity (IV, $\mathrm{mPa} \cdot \mathrm{s})$, peak viscosity $(\mathrm{PV}, \mathrm{mPa} \cdot \mathrm{s})$, final viscosity (FV, $\mathrm{mPa} \cdot \mathrm{s})$, breakdown ( $\mathrm{BD}, \mathrm{mPa} \cdot \mathrm{s})$, and setback (SB, $\mathrm{mPa} \cdot \mathrm{s})$. For each sample, the test was repeated twice.

\section{FT-Raman analysis and data manipulation}

Raman spectra were acquired using the FT-Raman module (NXR FT Raman) of a Nicolet 6700 FT-IR bench with 
TABLE 1. Water added, water absorption characteristics of doughs at $500 \mathrm{FU}$, and rheological parameters (G', G" and tan $\delta$ ) of doughs in the linear viscoelastic domain (strain $0.1 \%$ ) at $1 \mathrm{~Hz}$ frequency.

\begin{tabular}{lcccccc}
\hline Dough & $\begin{array}{c}\text { Water* } \\
(\mathrm{mL} / 50 \mathrm{~g})\end{array}$ & $\begin{array}{c}\text { WA } \\
(\%)\end{array}$ & $\begin{array}{c}\text { G } \\
(\mathrm{Pa})\end{array}$ & $\begin{array}{c}\text { G” } \\
(\mathrm{Pa})\end{array}$ & $\begin{array}{c}\tan \delta \\
(-)\end{array}$ \\
\hline SW & 25.9 & $52.5 \pm 0.2^{\mathrm{c}}$ & $32,490 \pm 689^{\mathrm{d}}$ & $14,780 \pm 309^{\mathrm{b}}$ & $0.449 \pm 0.009^{\mathrm{a}}$ \\
M & 40.5 & $79.6 \pm 0.2^{\mathrm{a}}$ & $71,720 \pm 6083^{\mathrm{a}}$ & $15,705 \pm 1562^{\mathrm{b}}$ & $0.218 \pm 0.003^{\mathrm{d}}$ \\
FB & 22.8 & $45.6 \pm 0.2^{\mathrm{d}}$ & $58,010 \pm 1213^{\mathrm{b}}$ & $26,350 \pm 551^{\mathrm{a}}$ & $0.454 \pm 0.009^{\mathrm{a}}$ \\
MFB & 29.5 & $58.0 \pm 0.2^{\mathrm{b}}$ & $50,320 \pm 3783^{\mathrm{c}}$ & $14,100 \pm 658^{\mathrm{b}}$ & $0.280 \pm 0.002^{\mathrm{b}}$ \\
IMFB & 19.5 & $38.2 \pm 0.2^{\mathrm{e}}$ & $96,420 \pm 20,195^{\mathrm{a}}$ & $24,802 \pm 5356^{\mathrm{a}}$ & $0.256 \pm 0.001^{\mathrm{c}}$ \\
\hline
\end{tabular}

$* \pm 0.1 \mathrm{~mL} / 50 \mathrm{~g}$; SW - soft wheat, M - maize, FB - field bean, MFB - maize-field bean formula, IMFB - improved maize-field bean formula, WA - water absorption, G' - storage modulus; G" - loss modulus; $\tan \delta$ - loss tangent. ${ }^{\text {a-e }}$ - different letters in columns indicate significant differences at $\alpha=0.05$.

an InGaAs detector and $\mathrm{CaF}_{2}$ beam splitter (Thermo Scientific, Madison, WI, USA). Samples were placed in stainless cubes and illuminated by means of a Nd:YAG excitation laser operating at $1064 \mathrm{~nm}$. The maximum laser power was $1 \mathrm{~W}$. In a single measurement, the spectra were recorded over the range of $3500-150 \mathrm{~cm}^{-1}$ and each resulting spectrum was given an average of 200 scans at $8 \mathrm{~cm}^{-1}$ of resolution. The analyzed spectra were averaged over the five registered spectra. Spectral data from sample scans were baseline-corrected using OMNIC software (version 8.2, Thermo Fischer Scientific Inc., Madison, WI, USA). Amide I band (1590-1720 $\left.\mathrm{cm}^{-1}\right)$, the S-S region (490-540 $\left.\mathrm{cm}^{-1}\right)$, aromatic amino acids environment: ratio of tyrosine doublet $\left(\mathrm{I}\left(850 \mathrm{~cm}^{-1}\right) / \mathrm{I}\left(830 \mathrm{~cm}^{-1}\right)\right)$ and tryptophan band $\left(\mathrm{I}\left(760 \mathrm{~cm}^{-1}\right)\right)$ were analyzed. To eliminate the effect of starch absorbance from the S-S region, starch spectra corresponding to each type of dough were collected and subtracted from dough spectra in the region 450$-550 \mathrm{~cm}^{-1}$ as follows: first starch band and that of the dough sample were peak normalized at maximum starch absorbance $\left(479 \mathrm{~cm}^{-1}\right)$, then the normalized band of starch was subtracted from the dough sample. Here, the S-S region $\left(490-540 \mathrm{~cm}^{-1}\right)$ band was baseline-corrected, surface normalized, and analyzed in order to estimate the structural conformation of disulfide bridges participating in the gluten-free protein network. The second derivatives of the amide I band and the S-S region were calculated using a five-point two-degree polynomial function in order to separate the overlapping bands and to identify the constituents of protein secondary structure and disulfide bridges conformation. In undertaking this, baseline-corrected and surface-normalized amide I bands and the S-S region were deconvoluted with Gaussian curves using ORIGIN software (version 8.0724 PRO, Origin Lab Corporation, Northampton, MA, USA). Differences in spectra were also calculated in order to confirm deconvolution results. The quality of the band deconvolution was indicated by $\mathrm{R}^{2}>0.99$, solution convergence, and $\chi^{2}<0.001$. The relative composition of amide I band secondary protein structures and types of structural conformation in the S-S region were expressed as percentage of the area of the fitted region manifested as a relative area of components centered at specific wavenumbers [Nawrocka et al., 2016b]. Amide I secondary structures: aggregates (AGR), pseudo $\beta$-sheet (P $\beta$-sh), $\beta$-sheet ( $\beta$-sh), $\alpha$-helix ( $\alpha$-hx), $\beta$-turn ( $\beta$-trn), and antiparallel $\beta$-sheet (A $\beta$-sh), as well as disulfide conformations: gauche-gauche-gauche (GGG), trans-gauche-gauche (TGG), and trans-gauche-trans (TGT) were assigned according to Nawrocka et al. [2016b] and Gómez et al. [2013]. To study the behavior of hydrophobic interactions inside the aromatic amino acids environment, the ratio $\mathrm{R}$ of the intensities of $\mathrm{I}\left(850 \mathrm{~cm}^{-1}\right) / \mathrm{I}\left(830 \mathrm{~cm}^{-1}\right)$ characteristic of tyrosine doublet, and $\mathrm{I}$ - the intensity $\mathrm{I}\left(760 \mathrm{~cm}^{-1}\right)$ characteristic of tryptophan band, were calculated.

\section{Statistical analysis}

The analysis of variance ANOVA and significant differences test (Tukey HSD test) were done to find differences between the rheological behavior of tested doughs and to estimate the effect of maize-field bean dough improvement. Principal component analysis (PCA) was used to highlight the relationships between viscoelastic behavior, pasting proprieties, and protein structure to explain the rheological behavior of GF doughs versus SW dough. Both statistical tests were carried out using XLSTAT software (version 2009.1.01, Addinsoft, USA) at a confidence level of $\alpha=0.05$. Results were expressed as means \pm standard deviations.

Correlations between rheological and structural parameters were checked by calculation of Pearson's coefficients (r). The following interpretation was assumed: $|\mathrm{r}| \geq 0.8$ - very strong correlation, $|\mathrm{r}| \geq 0.7$ strong correlation.

\section{RESULTS AND DISCUSSION}

\section{Rheological proprieties}

The rheological properties were determined in order to explain the structural features of the non-gluten doughs in comparison with dough made of soft wheat (control).

\section{Viscoelastic behavior}

Dough viscoelastic behavior was tested by ascertaining storage modulus ( $\left.G^{\prime}\right)$, loss modulus (G'), and loss tangent $(\tan \delta)$ as a function of frequency in the linear viscoelastic region (Figure 1). These three rheological properties show the nature of the food matrix. G' (elastic or storage modulus) relates to the material's ability to store energy elastically and G" (viscous or loss modulus) is related to the material's ability to dissipate stress through heat. Loss tangent $(\tan \delta)$ 
is the ratio of G" to G' which provides information on the relative contribution of viscous properties to elastic properties of the network [Tunick, 2011]. To compare the viscoelastic behavior of the different dough types, analysis of variance was conducted between G', G', and tan $\delta$ at $1 \mathrm{~Hz}$ of frequency. The results are summarized in Table 1.

All GF doughs had higher storage modulus than SW dough $(\mathrm{p}<0.05)$. These results were similar to those of Sivaramakrishnan et al. [2004] who reported higher storage modulus of GF rice-based doughs when compared with standard SW dough. FB supplementation of maize flour, however, significantly reduced the storage modulus from $71,720 \mathrm{~Pa}$ for $\mathrm{M}$ dough, to $50,320 \mathrm{~Pa}$ for the MFB formula. Treating maize hydrothermally as in the IMFB formula resulted in a significant increase in the solid character of GF dough compared to MFB dough. As stated by Lazaridou et al. [2007], the strengthening of GF dough by partly gelatinized ingredients improved elasticity and decreased extensibility as compared to SW dough. Here, the elasticity of GF doughs is directly related to the level of structuralization of the dough matrix and the value of $G^{\prime}$ increases with increasing level of structuralization. Both Lazaridou et al. [2007], and He \& Hoseney [1992] showed that the presence of interactions between the proteins and other components of dough was manifested by low values of G'. This may indicate the low ability

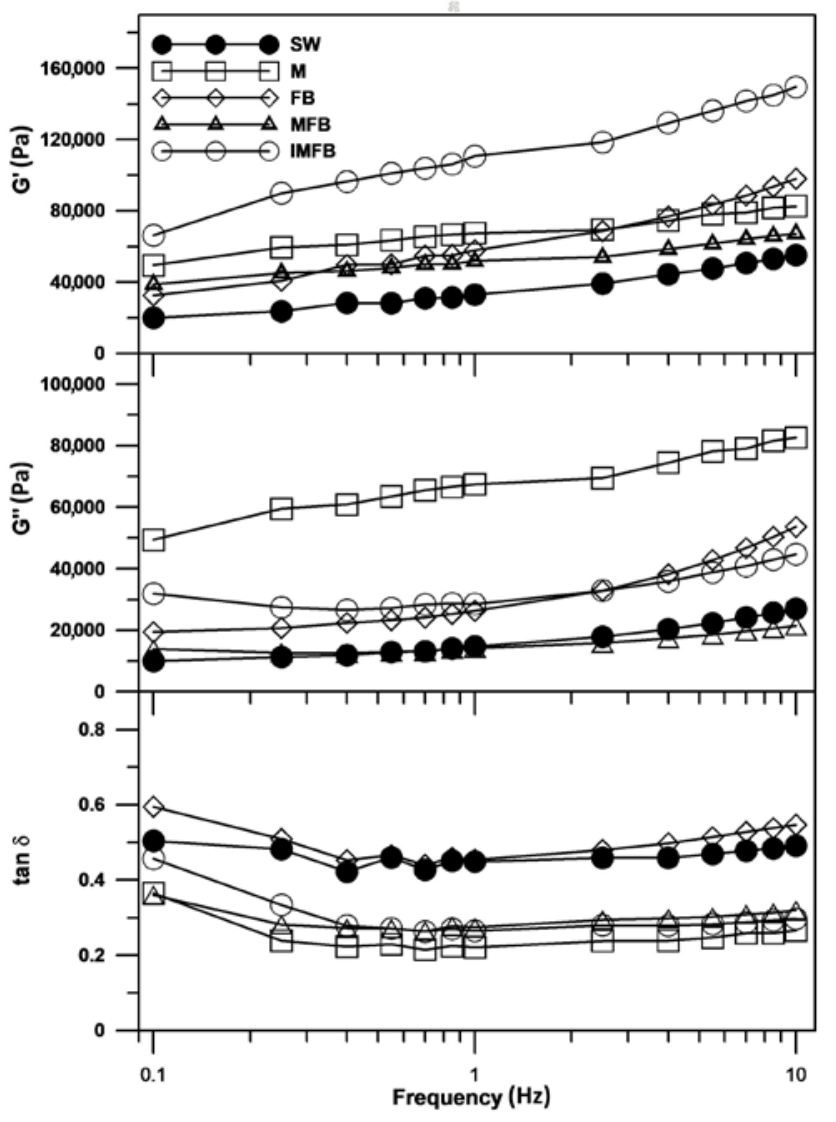

FIGURE 1. Rheological parameters (G' - storage modulus, G" - loss modulus, $\tan \delta$ - loss tangent) of doughs of soft wheat (SW), maize (M) field bean (FB), maize-filed bean (MFB) formula and improved MFB formula (IMFB) as a function of frequency. of non-gluten proteins to interact with other dough constituents, in comparison with gluten proteins, and might explain the low elasticity characterizing GF doughs.

The results of variance analysis showed insignificant differences between the loss modulus G" of SW, M, and MFB doughs (Table 1). Field bean flour supplementation of maize did not affect the viscous behavior of maize dough. FB and IMFB formula doughs gave G" values significantly higher than that of control SW. Moreover, the hydrothermal treatment resulted in the significant increase of the viscous modulus of IMFB formula dough, and this dough behaved similarly to high-protein FB dough.

The FB dough alone had a similar value of $\tan \delta$ to SW dough (Table 1) [Dus \& Kokini, 1990]. The low value of $\tan \delta$ registered for $\mathrm{M}$ dough indicates the strong contribution of the solid character in its structural formation. FB flour supplementation of M flour significantly increased the $\tan \delta$ value, which indicates that the cereal-legume formulation is characterized by an improved GF dough viscous behavior induced by reducing the solid-state contribution during its formation. This could be explained by the decreased matrix structuralization and indicates that the FB proteins had developed weaker chemical bonds with other constituents than between themselves. The hydrothermal treatment of the part of maize flour resulted in a significant decrease of $\tan \delta$ value of IMFB dough (1.09 times lower than that of MFB dough). Moreover, the addition of hydrothermally-treated maize flour to the GF bread recipe reduced the GF dough viscosity - as confirmed via the pasting characteristics of IMFB formula dough. The hydrothermally-treated maize flour may have acted as a binder of the dough matrix, improving its elastic component [Dib et al.,2018].

\section{Pasting proprieties}

During dough formation, starch acts as an inert filler in the dough's continuous protein matrix [Hřivna, 2018]. A dough rheological behavior is significantly affected by the specific properties of starch granules present on its surface [Larsson \& Eliasson, 1997]. Pasting properties of the studied doughs are presented in Table 2. As indicated, GT and IV values of all the tested doughs were similar. Here, SW and M doughs had the highest values of PV and BD, followed by the MFB formula and the improved IMFB doughs. FB dough showed the lowest PV and BD, indicating the highest stability of its paste due to a high protein content and the ability to absorb and hold water during heating. Ragaee \& Abdel-Aal [2006] suggested that high PV and BD values were related to the degree of starch granule swelling during heating. Here, the greater swelling capacity, the higher the PV values, hence, SW and M dough starch granules had a higher swelling capacity than the other doughs. These results are similar to the finding reported by Ragaee \& Abdel-Aal [2006] who found that SW flour gave high PV and BD values as compared to whole grain meals of durum wheat, barley, and sorghum.

During cooling, the viscosities of all doughs increased to an FV (Table 2), indicating the formation of a gel structure due to re-association between starch molecules. The high $\mathrm{SB}$ value is an indicator of the retrogradation and reordering 
TABLE 2. Pasting characteristics of wheat and gluten-free doughs.

\begin{tabular}{|c|c|c|c|c|c|c|}
\hline Dough & $\begin{array}{l}\text { GT } \\
\left({ }^{\circ} \mathrm{C}\right) \\
\end{array}$ & $\begin{array}{c}\mathrm{IV} \\
(\mathrm{mPa} \cdot \mathrm{s})\end{array}$ & $\begin{array}{c}\text { PV } \\
(\mathrm{mPa} \cdot \mathrm{s}) \\
\end{array}$ & $\begin{array}{c}\mathrm{FV} \\
(\mathrm{mPa} \cdot \mathrm{s})\end{array}$ & $\begin{array}{c}\mathrm{BD} \\
(\mathrm{mPa} \cdot \mathrm{s}) \\
\end{array}$ & $\begin{array}{c}\mathrm{SB} \\
(\mathrm{mPa} \cdot \mathrm{s}) \\
\end{array}$ \\
\hline SW & $73.5 \pm 2.2^{\mathrm{a}}$ & $14.5 \pm 0.7^{\mathrm{a}}$ & $223.5 \pm 13.4^{\mathrm{a}}$ & $333.0 \pm 12.7^{b}$ & $80.0 \pm 6.1^{\mathrm{a}}$ & $186.5 \pm 6.4^{\mathrm{a}}$ \\
\hline M & $74.5 \pm 0.1^{\mathrm{a}}$ & $13.5 \pm 2.1^{\mathrm{a}}$ & $213.5 \pm 14.8^{a}$ & $385.5 \pm 24.7^{\mathrm{a}}$ & $31.0 \pm 2.8^{\mathrm{b}}$ & $206.5 \pm 14.8^{a}$ \\
\hline $\mathrm{FB}$ & $72.5 \pm 0.3^{\mathrm{a}}$ & $13.0 \pm 1.4^{\mathrm{a}}$ & $117.5 \pm 4.9^{\mathrm{d}}$ & $185.0 \pm 8.5^{\mathrm{e}}$ & $2.5 \pm 0.7^{\mathrm{d}}$ & $78.0 \pm 4.2^{\mathrm{c}}$ \\
\hline $\mathrm{MFB}$ & $74.8 \pm 0.1^{\mathrm{a}}$ & $14.0 \pm 0.0^{\mathrm{a}}$ & $166.0 \pm 5.6^{\mathrm{b}}$ & $276.0 \pm 7.1^{\mathrm{c}}$ & $26.0 \pm 2.8^{\mathrm{b}}$ & $141.5 \pm 4.9^{\mathrm{b}}$ \\
\hline IMFB & $74.4 \pm 0.1^{\mathrm{a}}$ & $14.0 \pm 0.1^{\mathrm{a}}$ & $146.0 \pm 2.8^{c}$ & $245.0 \pm 5.6^{\mathrm{d}}$ & $18.0 \pm 0.1^{\mathrm{c}}$ & $122.0 \pm 83.0^{\mathrm{b}}$ \\
\hline
\end{tabular}

SW - soft wheat, M - maize, FB - field bean, MFB - maize-field bean formula, IMFB - improved maize-field bean formula, GT - gelatinization temperature, IV - initial viscosity, PV - peak viscosity, FV - final viscosity, BD - breakdown, SB - setback. ${ }^{\mathrm{a}-\mathrm{e}}$ - different letters in columns indicate significant differences at $\alpha=0.05$.

of starch molecules attributable to syneresis [Ragaee \& Abdel-Aal, 2006]. Accordingly, starch molecules of SW and M doughs with high SB values (186.5 and $206.5 \mathrm{mPa} \cdot \mathrm{s}$, respectively) induced high retrogradation rates. In contrast, FB dough with a low SB value (78.0 mPa.s) (Table 2) generated the lowest retrogradation rates due to having the lowest starch content.

Pasting properties of GF doughs were significantly affected by legume flour supplementation of maize. This brought about insignificant differences between MFB and IMFB doughs and significant differences to that of SW. Maize flour hydrothermal treatment in the IMFB dough resulted in a slight lowering of pasting parameter values compared to the MFB formula. This could be due to the alteration of the treated maize flour's pasting properties because of partial starch gelatinization resulting in bond formation between the chains of the amorphous region in starch molecules, as well as alteration of crystallinity induced by hydrothermal treatment, and thus by the starch retrogradation that occurred after cooling [Zavareze \& Guerra Dias, 2011]. Similar results were found by Dib et al. [2018] who studied the effect of hydrothermally-treated corn flour addition on the quality of corn/field bean gluten-free pasta.

\section{Structure of dough proteins}

Secondary structure of proteins involved in dough matrix development

Raman spectroscopic protein structure analysis was based on the following vibrational modes: amide A (NH stretching $\sim 3500 \mathrm{~cm}^{-1}$ ), amide B (NH stretching $\sim 3100 \mathrm{~cm}^{-1}$ ), and amide I to VII (I: $1600-1700 \mathrm{~cm}^{-1}$, II: $1480-1580 \mathrm{~cm}^{-1}$, III: $1230-1300 \mathrm{~cm}^{-1}$, IV: $625-770 \mathrm{~cm}^{-1}$, V: $640-800 \mathrm{~cm}^{-1}$, VI: 540-600 $\mathrm{cm}^{-1}$, VII: $\sim 200 \mathrm{~cm}^{-1}$ ) [Rygula et al., 2013]. The amide I band is usually used to estimate the type and the percentage of protein secondary structure in gluten matrices [Sivam et al., 2013].

Figure 2 shows the curve-fitted amide I bands (1590$-1720 \mathrm{~cm}^{-1}$ ). Peak numbers and position used in the curve fitting of each type of dough were determined according to results indicated by the second derivative (Figure 3). Distribution of secondary structures of doughs protein, calculated by deconvolution of FT-Raman spectra of the examined doughs is summarized in Table 3. The content of secondary structures of proteins for all doughs was evaluated by analysis of amide I differential spectra between GF and SW doughs (Figure 4) and between various gluten-free doughs (Figure 5). Here, amide I bands of maize and maize-based doughs showed a different shape in comparison with that of SW and FB doughs. This could indicate differences in the type and distribution of protein secondary structures (Figure 2). All amide I bands demonstrated a high absorbance around $\sim 1655 \mathrm{~cm}^{-1}$. This revealed that the secondary structure involved in the formation of the tested doughs was dominated by $\alpha$-helix conformation [Sivam et al., 2013].

Deconvolution of the amide I band of SW dough (Figure 2A) showed that the distribution of its secondary structures quantitative was predominated by $\alpha$-helix (43\%), followed by antiparallel $\beta$-sheet (18\%), $\beta$-turn $(15 \%), \beta$-sheet $(11 \%)$, pseudo $\beta$-sheet $(6 \%)$, and finally the aggregates $(7 \%)$ (Table 3). A previous study carried out by Nawrocka et al. [2015] uncovered differences in the secondary structure of native gluten proteins corresponding to $\alpha$-helices $(60 \%)$ and antiparallel $\beta$-sheet (8\%) content, as compared to the results obtained in our study where a relatively small fraction of pseudo $\beta$-sheet structure was found. The absence of random coil structure was also noted in this study. In contrast, Gómez et al. [2013] showed the participation of the random coil structure in the structuring of the native gluten backbone. The $\alpha$-helix structure was also predominant in this study.

The deconvolution of amide I band of maize dough (Figure 2B) revealed that its protein backbone was mainly formed by $\alpha$-helix (46\%) at levels close to that of SW dough [Pelton, 2000]. Aggregates (21\% found at $1602 \mathrm{~cm}^{-1}$ ) and $\beta$-sheets (19\% at 1629 and $1639 \mathrm{~cm}^{-1}$ ) followed $\alpha$-helix in the maintaining of maize dough protein networks (Table 3). These two structures were, respectively, 3.0 and 1.7 times more abundant than in SW. Fractions of antiparallel $\beta$-sheet (8\%), followed by $\beta$-turn structure (6\%) were lower than in control SW dough, and pseudo $\beta$-sheet structures were not evident. The FT-IR spectroscopic work of Mejia et al. [2007] on the secondary structure of viscoelastic polymers of maize $\alpha$-zein and wheat gluten proteins showed that the native structure of maize $\alpha$-zein was mainly composed of $\alpha$-helices $(\sim 68 \%)$. Similar results were reported by Matsushima et al. [1997]. 

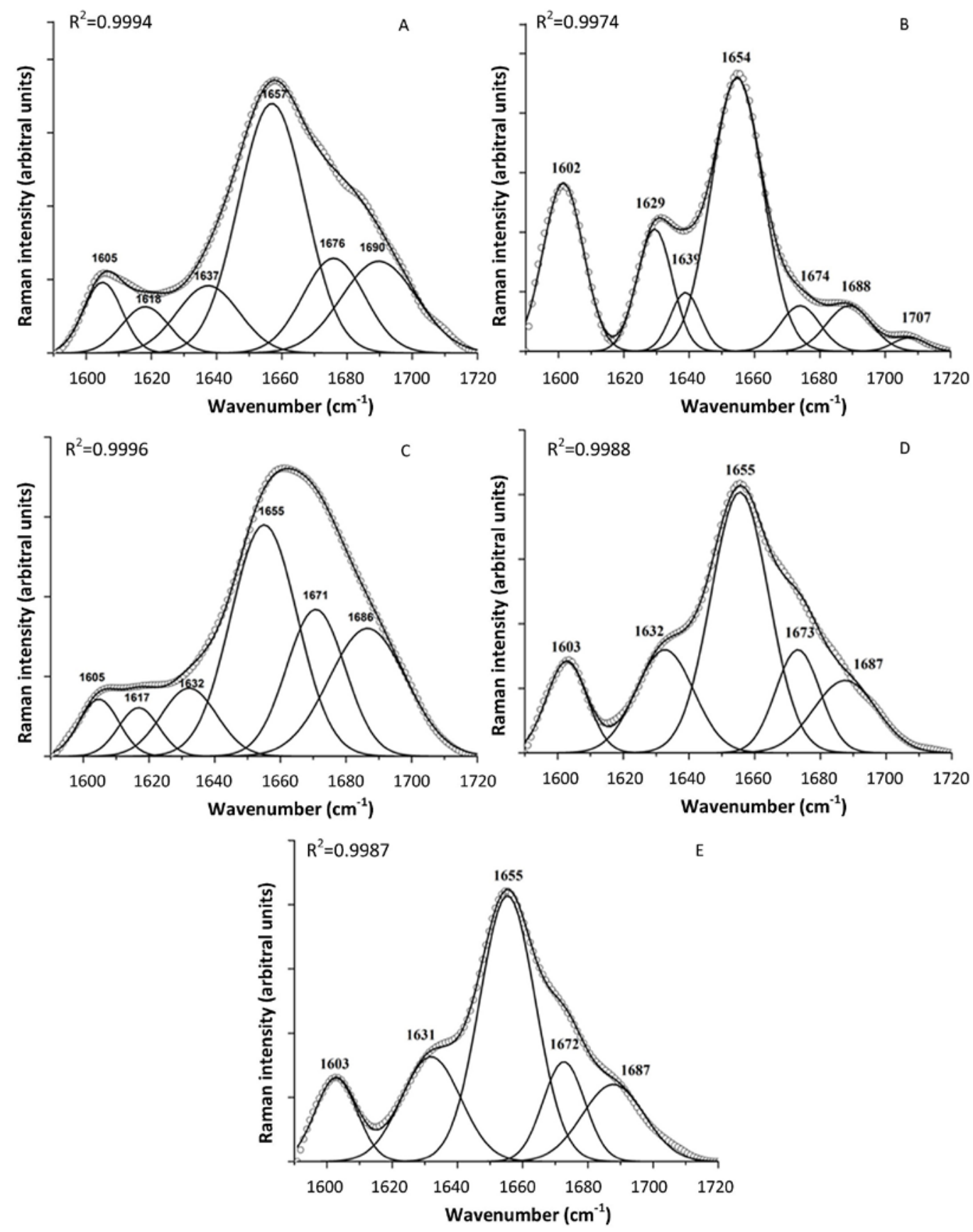

FIGURE 2. Deconvoluted Raman spectra in the area representing amide I band (1590- $\left.1720 \mathrm{~cm}^{-1}\right)$ of doughs: (A) soft wheat, SW, (B) maize, M, (C) field bean, FB, (D) maize-filed bean, MFB, formula, (E) improved MFB formula, IMFB. Solid line - fitted curve, open circles - original data.

The secondary structure of FB dough (Figure 2C) consisted of the dominant $\alpha$-helix structure at $37 \%$ (1.16 times lower than that in SW dough), $24 \%$ of antiparallel $\beta$-sheet (at $\left.1685 \mathrm{~cm}^{-1}\right)$, and $21 \%$ of $\beta$-turn $\left(1671 \mathrm{~cm}^{-1}\right)(1.33$ and 1.4 times higher than in SW control dough). Although an increase was observed in the case of FB antiparallel $\beta$-sheet, no statistical differences were found between FB and SW. Amounts of aggregates (5\%), pseudo $\beta$-sheet $(4 \%)$, and $\beta$-sheet $(9 \%)$ were close to that of the control dough (Table 3). FT-IR spectroscopy of field bean dough showed the dominance of the $\alpha$-helix structure $(45 \%)$ in the formation of its protein network [Fetouhi et al., 2019].
The deconvolution of the amide I band of MFB dough (Figure 2D) indicated that the replacement of $1 / 3$ of the $\mathrm{M}$ flour with FB led to a decrease in the aggregate fraction from 21 to $11 \%$. Furthermore, antiparallel $\beta$-sheet $\left(1687 \mathrm{~cm}^{-1}\right)$ and $\beta$-turn $\left(1673 \mathrm{~cm}^{-1}\right)$ content increased, respectively, from 8 to $13 \%$ and from 6 to $14 \%$ as compared with M dough (Table 3). SW dough showed lower values of $\beta$-sheet than MBF and IMBF but comparable amounts of $\beta$-turn. Similar values of $\alpha$-helix and $\beta$-sheet and pseudo $\beta$-sheet fractions were found in $\mathrm{M}, \mathrm{MBF}$, and IMBF doughs which differed significantly from FB and SW dough. Thus, the effect of maize structural composition seems to be important in this analysis. 

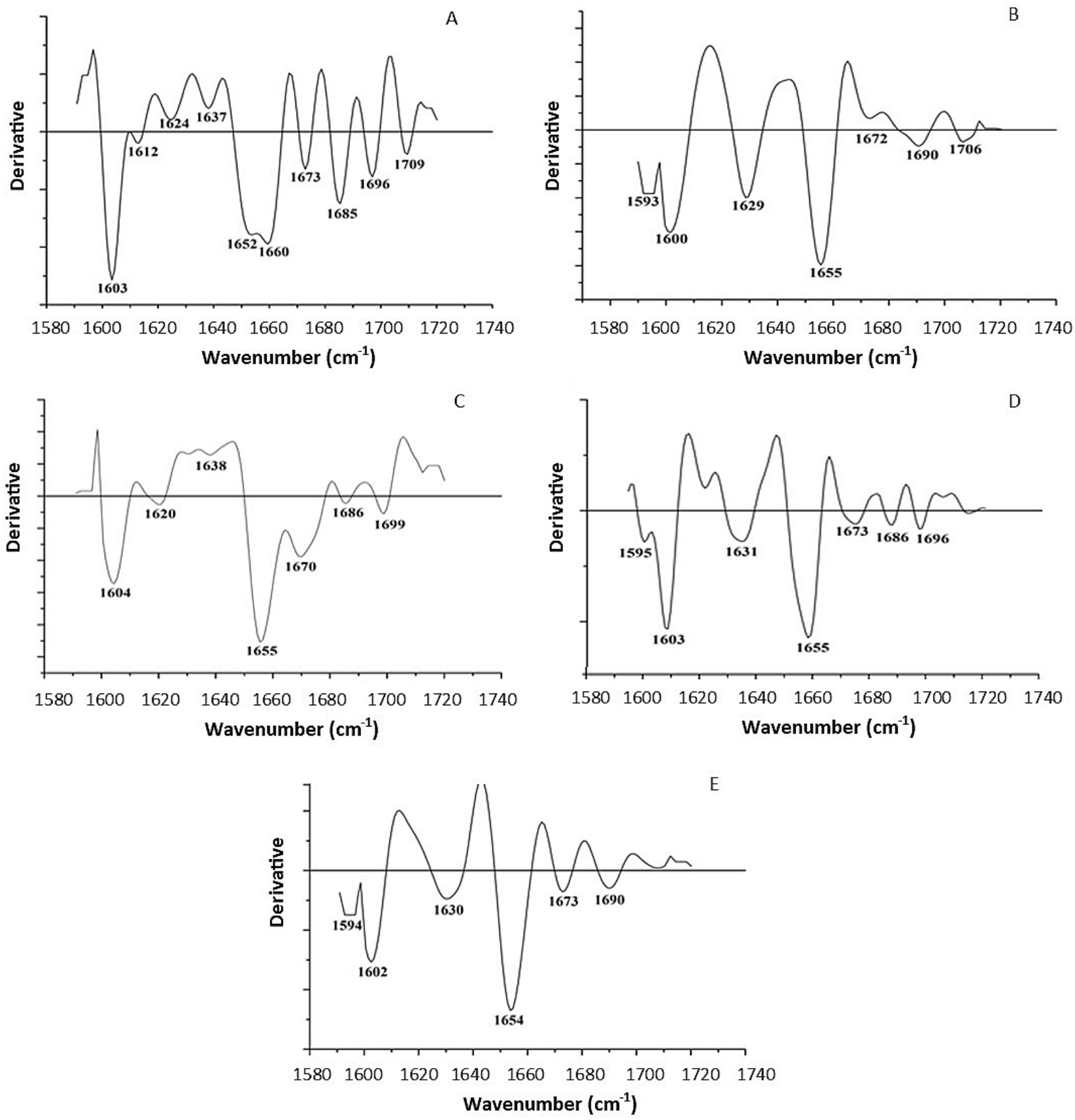

FIGURE 3. Second derivative of Raman spectra of doughs in amide I region: 1720-1590 $\mathrm{cm}^{-1}$ : (A) soft wheat, SW, (B) maize, M, (C) field bean, FB, (D) maize-filed bean, MFB, formula, and (E) improved MFB formula, IMFB, dough.

By comparing the curve fitting results of the IMFB dough amide I band (Figure 2E) with the formula without improver and with SW, it is noticeable that the incorporation of hydrothermally-treated maize flour in the GF bread formula caused a slight increase in the amount of antiparallel $\beta$-sheet structure $\left(1687 \mathrm{~cm}^{-1}\right)$ from 13 to $15 \%$ (no statistical differences) and a slight decrease in the content of $\beta$-turn $\left(12 \%-1672 \mathrm{~cm}^{-1}\right)$ approaching SW dough. No significant changes were noted for aggregates, $\beta$-sheet, and $\alpha$-helix (Table 3 ). This effect was comparable to that of SW dough, but lower than that for $\mathrm{M}$ dough. The addition of hydrothermally-treated maize flour had no effect on the type of the secondary structure of dough.

\section{Aromatic amino-acids chains}

The behavior of the side groups is often used in conformational studies of proteins. In addition to cysteine, tyrosine and tryptophan residues were also involved in maintaining the dough protein backbone [Wieser, 2007].

The $\mathrm{R}$ ratio of the doublet intensity of tyrosine is a direct measure of the negative charge state of phenolic oxygen and that of the tyrosine environment. Overman et al. [1994] suggested that $\mathrm{R}$ was sensitive to the hydrogen bonding state of a phenoxyl tyrosine mixture. This can be interpreted as follows: if $\mathrm{R}=0.30$, the $\mathrm{OH}$ proton functions as donor of a strong hydrogen bond; at $\mathrm{R}=2.5$, the $\mathrm{OH}$ oxygen functions as an 

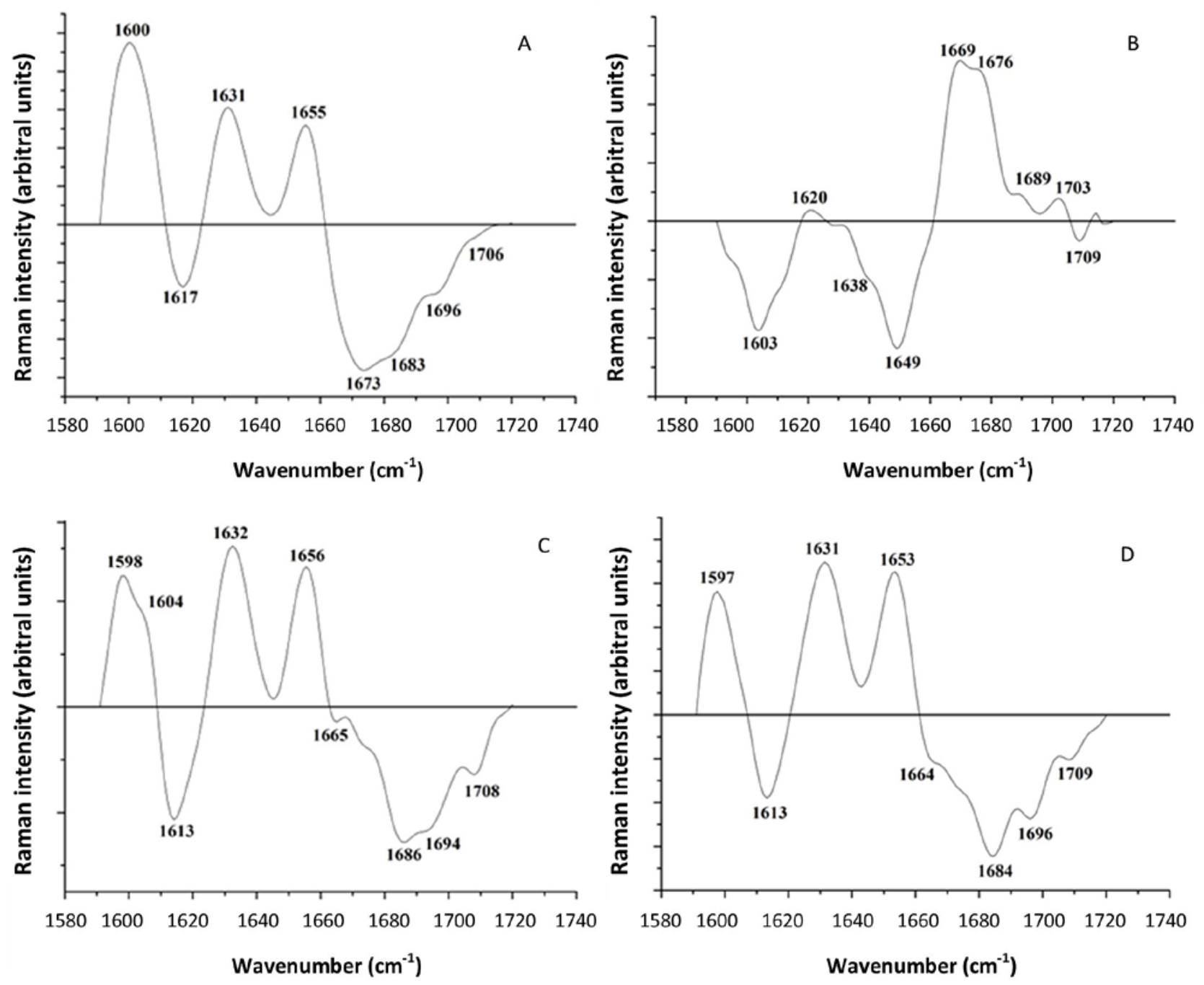

FIGURE 4. Raman differential spectra in amide I region between (A) maize, M; (B) field bean, FB; (C) maize-field bean, MFB, formula; and (D) improved MFB formula, IMFB, doughs and soft wheat, SW, dough.

acceptor of a strong hydrogen bond, while $\mathrm{R}=1.25$ if the $\mathrm{OH}$ group functions as a donor and an acceptor, as for solvent-exposed tyrosine. Herrero [2008] demonstrated that the tyrosine residue $\mathrm{OH}$ group behaved as an acceptor in a strong $\mathrm{H}$-bond when $\mathrm{R}$ was higher than 2.5 and as $\mathrm{H}$-bond donor when $\mathrm{R}$ was lower than 0.3 . The $\mathrm{R}$ value is also a good indicator of the location of the tyrosyl group exposed or buried within the protein structure [Ferrer et al., 2011]. When the intensity I at $850 \mathrm{~cm}^{-1}$ is higher than that at $830 \mathrm{~cm}^{-1}$, tyrosyl residues are exposed and act as a positive charge, facilitating local repulsion between protein molecules and inducing a change in the tertiary protein structure. If I at $850 \mathrm{~cm}^{-1}$ is smaller than that $830 \mathrm{~cm}^{-1}$, this indicates that the tyrosyl groups are buried in the protein backbone and that these groups participate in protein folding by inter- and intra-molecular hydrogen bonds [Wang et al., 2017; Herrero, 2008].

The ratio of $\mathrm{I}\left(850 \mathrm{~cm}^{-1}\right) / \mathrm{I}\left(830 \mathrm{~cm}^{-1}\right)$ values $(\mathrm{R})$ calculated for the tested doughs (Table 3 ) was $\geq 2.5$ for SW (3.41), M (2.79), and IMFB formula (2.52) doughs. In the case of MFB dough, the ratio approximated 2.5. Only FB dough had an $\mathrm{R}$ ratio between 2.5 and 0.3 (2.37). These results indicate that for all dough types, the tyrosyl residues were exposed and acted as a positive charge facilitating local repulsion between the protein molecules responsible for tertiary protein structure changes. The SW sample showed the highest $R$ value in this study $(R \geq 2.5)$, indicating that tyrosyl residues in wheat dough behave as an exposed acceptor in a strong $\mathrm{H}$-bond. This value was higher than those reported by Nawrocka et al. [2016b] and Ferrer et al. [2011] for gluten proteins ( 0.88 and 1.29 , respectively). This difference could be due to the different character of molecular interactions triggered by the presence of various amounts of protein in raw materials applied in GF dough formulations that favor the exposition of tyrosine residues at protein structure surfaces.

All gluten-free doughs demonstrated lower R ratio values than the SW dough. The highest value was observed for maize dough, while the lowest one for field bean dough (Table 3). These results indicate that the tyrosine $\mathrm{OH}$ groups of gluten-free doughs, except for the protein-rich field bean doughs, behaved as acceptors in a strong H-bond. At the same time, the $\mathrm{OH}$ groups of tyrosine residues in field bean dough behaved as both proton donors and acceptors. 

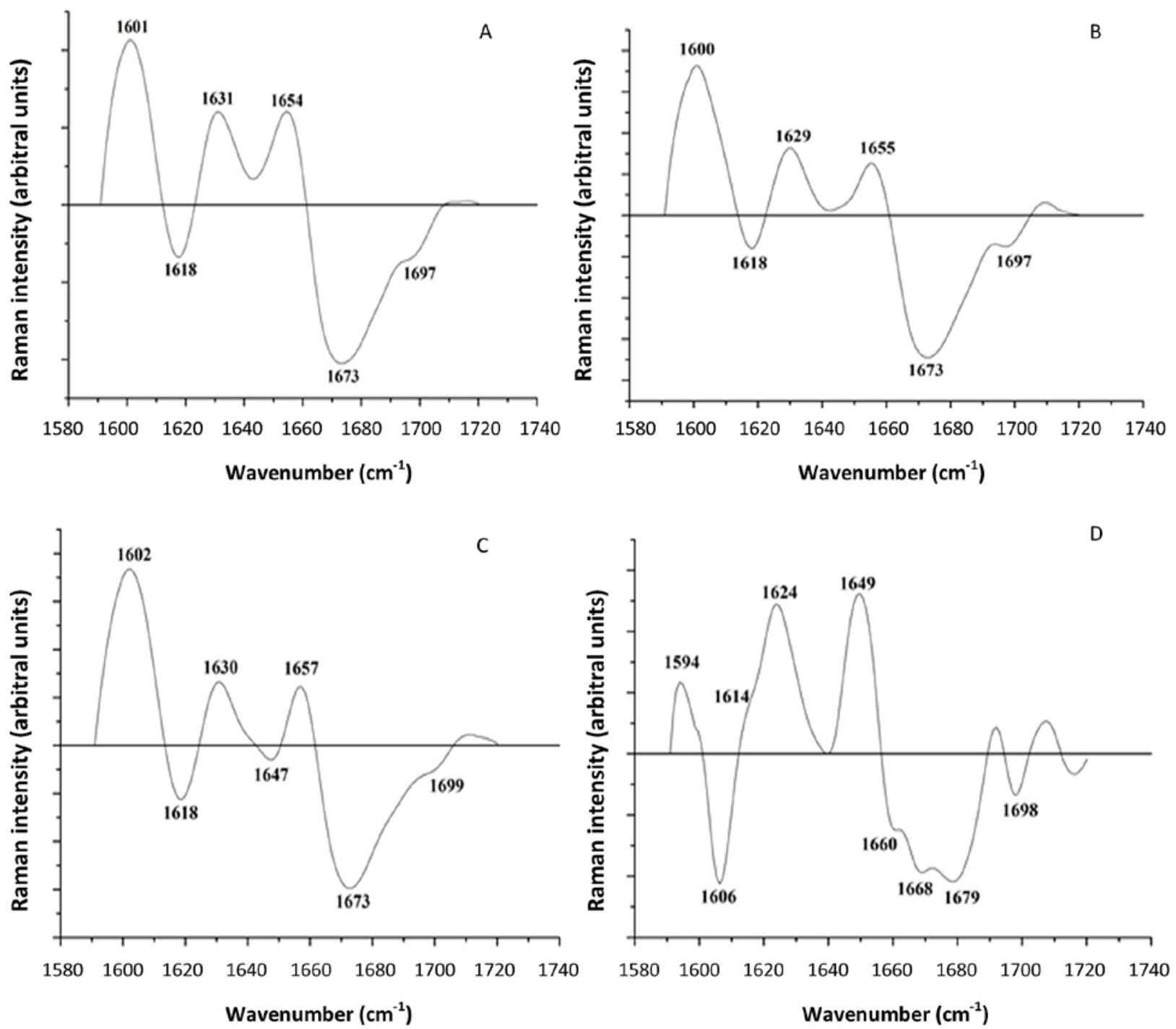

FIGURE 5. Raman differential spectra in amide I region between maize M and the following preparations: (A) field bean, FB; (B) maize-field bean, MFB; and (C) improved MFB formula, IMFB; (D) shows the differential spectrum between amide I region of IMFB and MFB doughs.

TABLE 3. Distribution of secondary structures of doughs protein calculated by deconvolution of FT-Raman spectra in the amide I region and aromatic amino acids (tyrosine and tryptophan) structure of doughs. Values calculated on the basis of 5 averaged spectra consisting of 200 scans. The quality of band deconvolution was indicated by $\mathrm{R}^{2}>0.99$, solution convergence and $\chi 2$ were $<0.001$.

\begin{tabular}{|c|c|c|c|c|c|c|c|c|}
\hline Sample & $\begin{array}{c}\text { AGR } \\
(\%)\end{array}$ & $\begin{array}{c}\mathrm{P} \beta \text {-sh } \\
(\%)\end{array}$ & $\begin{array}{l}\beta \text {-sh } \\
(\%)\end{array}$ & $\begin{array}{c}\alpha-h x \\
(\%)\end{array}$ & $\begin{array}{c}\beta-\operatorname{trn} \\
(\%)\end{array}$ & $\begin{array}{c}\mathrm{A} \beta \text {-sh } \\
(\%)\end{array}$ & $\begin{array}{c}\mathrm{R} \\
\mathrm{I}(850) / \mathrm{I}(830)\end{array}$ & $\begin{array}{c}\mathrm{I} \\
(760)\end{array}$ \\
\hline SW & $7^{b}$ & $6^{\mathrm{a}}$ & $11^{\mathrm{b}}$ & $43^{b}$ & $15^{\mathrm{b}}$ & $18^{\mathrm{ab}}$ & $3.41^{\mathrm{a}}$ & $0.37^{\mathrm{b}}$ \\
\hline M & $21^{\mathrm{a}}$ & $0^{\mathrm{b}}$ & $19^{\mathrm{a}}$ & $46^{\mathrm{a}}$ & $6^{c}$ & $8^{c}$ & $2.79^{\mathrm{b}}$ & $0.44^{\mathrm{ab}}$ \\
\hline FB & $5^{c}$ & $4^{\mathrm{a}}$ & $9^{c}$ & $37^{c}$ & $21^{\mathrm{a}}$ & $24^{\mathrm{a}}$ & $2.37^{c}$ & $0.60^{\mathrm{a}}$ \\
\hline MFB & $11^{\mathrm{b}}$ & $0^{\mathrm{b}}$ & $17^{\mathrm{a}}$ & $45^{\mathrm{ab}}$ & $14^{\mathrm{b}}$ & $13^{\mathrm{bc}}$ & $2.46^{\mathrm{c}}$ & $0.60^{\mathrm{a}}$ \\
\hline IMFB & $10^{\mathrm{bc}}$ & $0^{\mathrm{b}}$ & $19^{a}$ & $44^{b}$ & $12^{\mathrm{b}}$ & $15^{\mathrm{b}}$ & $2.52^{\mathrm{bc}}$ & $0.60^{\mathrm{a}}$ \\
\hline
\end{tabular}

SW - soft wheat, M - maize, FB - field bean, MFB - maize-field bean formula, IMFB - improved maize-field bean formula, AGR - aggregates, $\mathrm{P} \beta$-sh - pseudo $\beta$-sheet, $\beta$-sh $-\beta$-sheet, $\alpha$-hx $-\alpha$-helix, $\beta$-trn $-\beta$-turn, $\mathrm{A} \beta$-sh - antiparallel $\beta$-sheet. Deconvolution granted accuracy higher than $\pm 1 \%$, $\mathrm{R}$-ratio of the doublet intensity of tyrosine, I - spectrum intensity characteristic of the tryptophan band. Ratios are taken from a spectrum resulting from an average of 5 spectra containing 200 scans at $8 \mathrm{~cm}^{-1}$ of resolution. ${ }^{\mathrm{a}-\mathrm{c}}$ - different letters in column indicate significant differences at $\alpha=0.05$. 

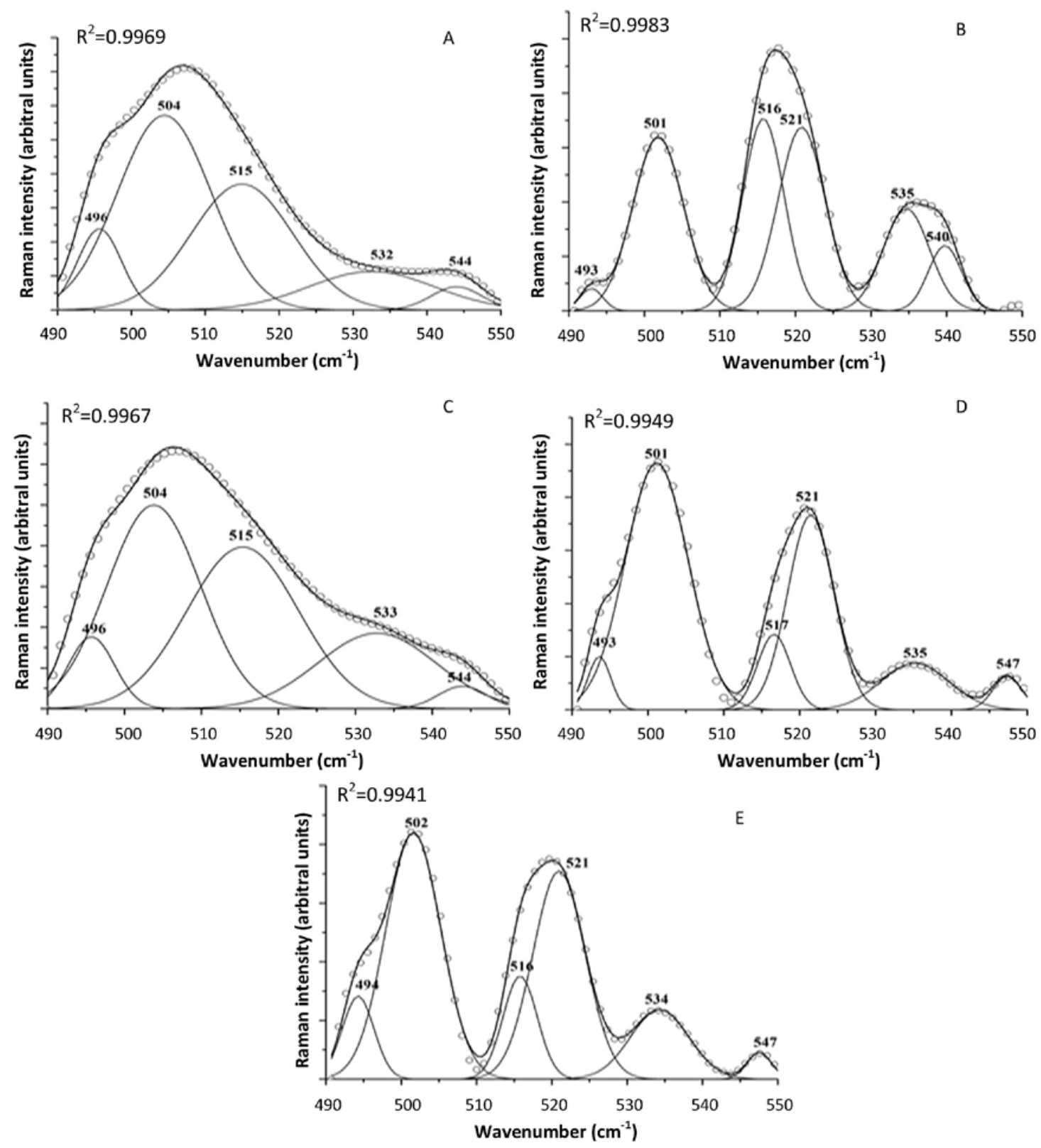

FIGURE 6. Deconvoluted Raman spectra in the area representing S-S region of doughs (490-550 $\mathrm{cm}^{-1}$ ): (A) soft wheat, SW dough, (B) maize, M dough, (C) field bean, FB dough, (D) maize-filed bean formula, MFB dough, and (E) maize-filed bean improved formula, IMFB dough. Solid line - fitted curve, open circles - original data.

The tryptophan band with the maximum at $760 \mathrm{~cm}^{-1}$ is used to indicate the strength of H-bonding and the hydrophobicity of indole ring environments [Linlaud et al., 2011]. The increase in its intensity indicates the 'buriedness' of tryptophan residues inside protein molecules, whereas the decrease shows the release of these residues from the hydrophobic zone and their contribution in the formation of disordered protein structures [Nawrocka et al., 2015].

We found that the tryptophan band I(760) intensity shown by the SW dough $(0.37)$ was higher compared to the gluten protein $(0.087$ or 0.167$)$ presented by Nawrocka et al. [2015, 2016a]. FB, MFB, and IMFB formula doughs had similar I(760) intensities (0.60) (Table 3), which were significantly higher $(\mathrm{p}<0.05)$ than that of SW by 1.62 times and insignificantly higher $(\mathrm{p} \geq 0.05)$ than that of $\mathrm{M}$ dough (0.44) by 1.36 times. This difference indicates that supplementing maize flour with field bean and the hydrothermal treatment of part of the maize flour in GF bread dough increased tryptophan residue buriedness inside the protein backbone.

\section{Disulfide bridges conformation}

In bread-dough-making, disulfide bridges participate in the formation and development of the protein network, especially the tertiary structure [Wieser, 2007]. Gómez et al. [2013] and Ferrer et al. [2011] stated that the S-S bridge conformation played a major role in the functional properties of gluten dough. Thus, we analyzed the disulfide bridge region in GF doughs and compared them with that of SW dough. Disulfide bridge conformation distribution is shown in Table 4, while Figure 6 reveals the deconvoluted S-S dough regions. 
TABLE 4. Distribution of disulfide bridge conformations of the tested doughs with positions of band maxima (in $\mathrm{cm}^{-1}$ ) in brackets. Values calculated on the basis of 5 averaged spectra consisting of 200 scans. The quality of band deconvolution was indicated by $\mathrm{R}^{2}>0.99$, solution convergence and $\chi 2$ was $<0.001$.

\begin{tabular}{lcccc}
\hline Dough & GGG $(\%)$ & TGG $(\%)$ & TGT $(\%)$ \\
\hline SW & $51^{\mathrm{a}}(496-504)$ & $35^{\mathrm{b}}(515)$ & $14^{\mathrm{b}}(532-544)$ \\
$\mathrm{M}$ & $28^{\mathrm{c}}(493-501)$ & $51^{\mathrm{a}}(516-521)$ & $21^{\mathrm{a}}(535-540)$ \\
FB & $41^{\mathrm{b}}(496-504)$ & $36^{\mathrm{b}}(515)$ & $20^{\mathrm{a}}(532-543)$ \\
MFB & $51^{\mathrm{a}}(493-501)$ & $36^{\mathrm{b}}(517-521)$ & $13^{\mathrm{b}}(535-547)$ \\
IMFB & $45^{\mathrm{ab}}(494-502)$ & $41^{\mathrm{ab}}(516-521)$ & $14^{\mathrm{b}}(534-547)$ \\
\hline
\end{tabular}

SW - soft wheat, M - maize, FB - field bean, MFB - maize-field bean formula, IMFB - improved maize-field bean formula, GGG - gauche-gauche-gauche, TGG - trans-gauche-gauche, TGT - trans-gauche-trans ${ }^{\mathrm{a}-\mathrm{c}}$ - different letters in column indicate significant differences at $\alpha=0.05$.

The analysis of the S-S bond conformation of the control SW dough showed the predominance of the GGG conformation $(51 \%)$, followed by TGG (35\%) (Table 4). Nawrocka et al. [2015] made the same observation and demonstrated the predominance of these two types of conformations in the formation of a gluten network. Moreover, Gómez et al. [2013] analyzed the effect of fiber addition on gluten quality and demonstrated that the S-S bridge structure of the gluten network was predominated by GGG and TGT structures and lacked TGG conformation. The predominance of the GGG conformation indicates that the SW dough protein network is more structurally stable [Nawrocka et al., 2016b].

When comparing the gluten-free doughs with the control, we noted that only the $\mathrm{M}$ dough differed significantly in the percentage distribution of the S-S bridge conformations and that it was characterized by a predominance of the TGG conformation (1.5 times higher than of SW). However, a small amount of GGG fraction (1.8 times lower than of SW) and TGT (1.5 times higher than of SW) conformations was observed as well. Nawrocka et al. [2016b] believed those results indicate that the maize dough protein network is characterized by less stable disulfide bridges. Moreover, the lower protein content in maize could explain the fragility of the $\mathrm{M}$ dough protein network when compared to SW dough.

The other types of doughs showed disulfide bridge conformation distribution close in type to SW dough, which was characterized by a predominance of the GGG conformation, followed by TGG, then TGT - but with different fraction ratios.

The quantitative distribution of the three types of conformations in FB dough was similar to SW control dough. When comparing distribution percentages of the three forms of S-S bridges, we observed that the fractions of TGG (36\%) were similar while TGT (20\%) conformations were higher than that of the control, but the GGG conformations (41\%) were lower (Table 4). These results suggest that during FB dough protein network development, the formation of the GGT and TGT conformations was in detriment of GGG conformation, which, in turn, could explain the less stable structure of the field bean dough (beyond its greater protein content).
The conformation of MFB dough S-S bridges was closer to that obtained for the SW control: GGG (51 close to 53\%), TGG (36 close to $35 \%$ ), and TGT (13 close to $14 \%$ ), respectively (Table 4). Therefore, the substitution of maize flour with field bean improved the S-S bridges distribution, and promoted the formation of more stable structures. The addition of hydrothermally-treated maize flour to the IMFB dough only slightly affected the distribution of disulfide bridge conformation.

\section{Relationship between structural properties and rheological behavior of gluten-free bread doughs}

The poor quality of the GF dough and its low rheological behavior could be due to the structural mechanisms of non-gluten protein network dough development. Thus, using PCA, we studied the relationships between the rheological parameters, the types of secondary structures, aromatic amino-acid environment properties, and disulfide bridge conformations.

PCA clearly resolved data into four principal components, which explained 49.21 (PC1), 30.31 (PC2), 15.75 (PC3), and $4.72 \%$ (PC4) of the variation. The results obtained for components PC1 and PC2 were retained because they accounted for $79.52 \%$ of the total variance. PC scores and loadings of PC1 against PC2 are shown in Figure 7. The correlation matrix between rheological and structural parameters of the tested doughs is presented in Table 5.

The predominance of the first principal component (PC1) was defined by the $\beta$-turn content because this parameter showed a high correlation with this factor $(r=0.970)$ and divided the plane vertically (Figure 7). The second principal component (PC2) was defined by the BD parameter $(\mathrm{r}=0.923)$ and divided the plane horizontally. As seen in the PCA scores (Figure 7A), PC1 shows a great variability. Being on the positive side of PC1, FB and IMFB doughs were seen to have similar properties to those of SW. This indicates that they had similar properties dependent on $\beta$-turn content. Moreover, the application of hydrothermally-treated maize flour in the IMFB formula affected $\beta$-turn structure content. Regarding the PC2 axis as defined by BD, all gluten-free doughs were located in the negative side, hence demonstrating that the differences in the rheological behavior between SW and GF doughs were highly related to the pasting properties (BD) rather than to the viscoelastic properties as indicated by G' and G'.

WA was considered as a mixing parameter and a factor that affected dough structure during its formation. It was strongly positively correlated with AGR $(r=0.846)$ and strongly negatively correlated with $A \beta$-sheet content $(r=-0.721)$ (Table 5). This indicates that the high water absorption of GF dough promotes the formation of aggregates to the detriment of $A \beta$-sheet fabrication. This suggestion is confirmed by the strong negative correlation between AGR and A $\beta$-sheet content. Here, a strong negative correlation was found between WA and AGR amount, indicating that differences do exist between mechanisms of gluten and non-gluten protein network development.

The storage modulus G' was influenced only by $\mathrm{P} \beta$-sheet amount $(r=-0.712)$. This indicates that the stiff and rigid skeleton of non-gluten doughs is due to the low capacity of GF doughs to form this kind of the secondary structure during matrix development. 

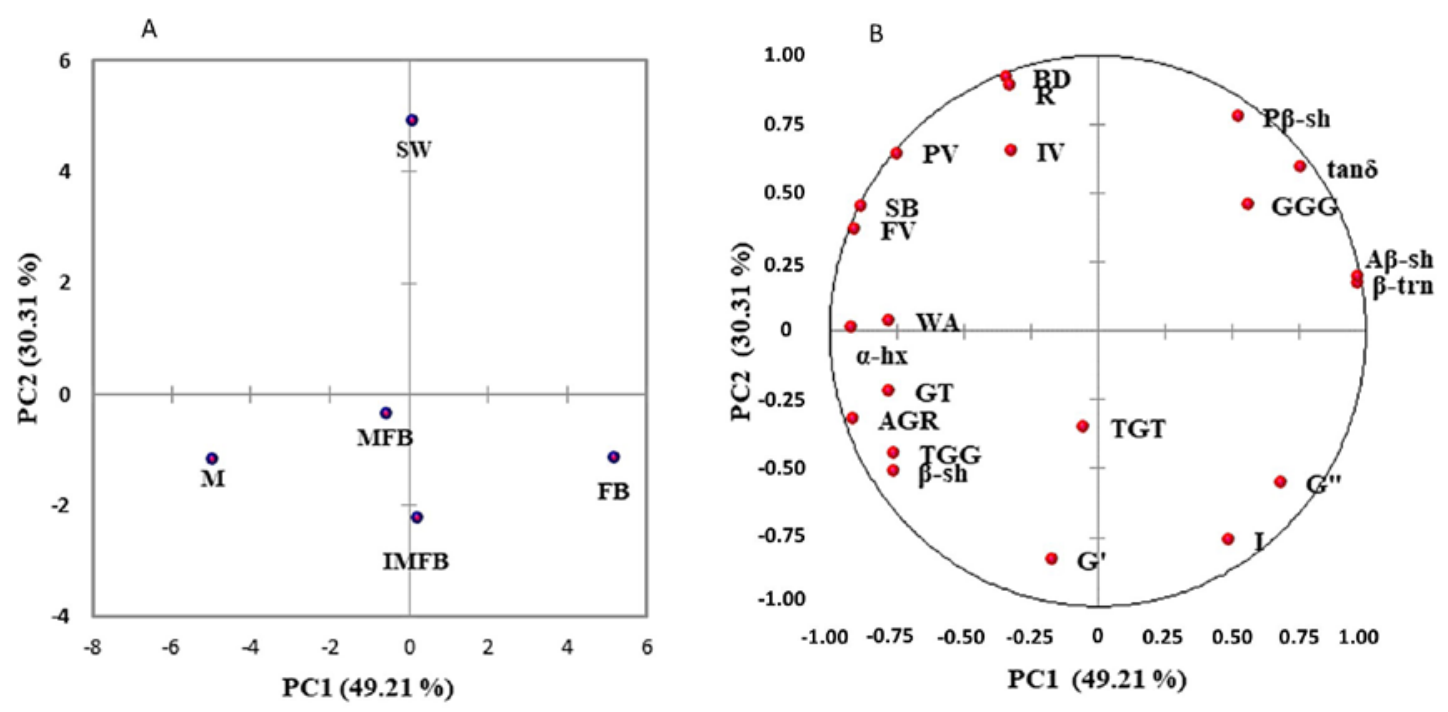

FIGURE 7. Principal component analysis (PCA) of rheological (A) and structural (B) characteristics of the tested doughs: soft wheat, SW; maize, M; field bean, FB; maize-filed bean formula, MFB; maize-filed bean improved formula, IMFB. WA - water absorption, G' - storage modulus; G" - loss modulus; $\tan \delta$ - loss tangent, GT - gelatinization temperature, IV - initial viscosity, PV - peak viscosity, FV - final viscosity, BD - breakdown, SB - setback, AGR - aggregates, P $\beta$-sh - pseudo $\beta$-sheet, $\beta$-sh - $\beta$-sheet, $\alpha$-hx - $\alpha$-helix, $\beta$-trn - $\beta$-turn, A $\beta$-sh - antiparallel $\beta$-sheet, GGG - gauche-gauche-gauche, TGG - trans-gauche-gauche, TGT - trans-gauche-trans, R - ratio of the doublet intensity of tyrosine, and I - spectrum intensity characteristic of the tryptophan band.

Tan $\delta$ was strongly and positively correlated with the amounts of $\mathrm{P} \beta$-sheet $(\mathrm{r}=0.947), \mathrm{A} \beta$-sheet $(\mathrm{r}=0.885)$, and $\beta$-turn $(\mathrm{r}=0.837)$, while a strong negative correlation was observed between AGR $(\mathrm{r}=-0.817)$, $\beta$-sheet $(\mathrm{r}=-0.983)$, and $\alpha$-helix $(\mathrm{r}=-0.794)$ content (Table 5). Fetouhi et al. [2019] observed similar correlations between $\tan \delta$ and the amounts of $\beta$-turn, $\beta$-sheet, and $\alpha$-helix for GF doughs based on a rice-field bean formula. They explained that these results were due to the great tendency of gluten-free ingredients to form $\alpha$-helix and $\beta$-sheet structures, hence strongly promoting protein structuralization. This is in direct relationship with low values of $\tan \delta$ and the high inflexibility and rigidness displayed during gluten-free dough formation. In our study, low $\tan \delta$ values of GF doughs could have occurred due to the low capacity of non-gluten proteins to form $\mathrm{P} \beta$-sheet structures (positive correlation) where these types of structures may participate in the formation of $\beta$-sheet structuring (negative correlation). The positive correlation between $\tan \delta$ and $A \beta$-sheet $(r=0.885)$ and $\beta$-turn content $(\mathrm{r}=0.837)$ and the strong negative correlation between $A \beta$-sheet and $\alpha$-helix $(r=-0.940)$ content demonstrate that the mechanism of non-gluten protein network formation is based on the formation of $\beta$-sheet and $\alpha$-helix structures, hence, not only to the detriment of $\beta$-turn, but also at the expense of the $A \beta$-sheet structure.

We noted the effect of the disulfide bridge conformational changes on the rheological behavior of gluten. According to the PCA score (Figure 7B) and correlation matrix (Table 5), the correlation between GGG and TGG $(r=-0.946)$ and TGT $(\mathrm{r}=-0.818)$ content was strongly negative. This indicates the more intense participation of TGG and TGT disulfide bridges in the formation of the non-gluten protein matrix rather than the GGG conformation that was noted in the case of gluten proteins [Nawrocka et al., 2015].
No direct relationship between the S-S bridges conformation and rheological behavior of GF doughs was observed based on the PCA plot (Figure 7B) or correlation matrix. We presume that disulfide bridge conformation indirectly participated in the rheological behavior because this affected the type of secondary structure forming the non-gluten protein matrix. The strong positive correlation observed between TGG content and AGR $(r=0.924)$ was accompanied by a negative correlation with $A \beta$-sheet $(r=-0.751)$ and $\beta$-turn $(r=-0.852)$. GGG conformation was also negatively correlated with AGR structure content $(\mathrm{r}=-0.813)$ (Table 5). All these results indicate the low tendency of non-gluten proteins to form $\beta$-turn and $A \beta$-sheet structures, and the high capacity of these types of proteins to form the AGR structures that are promoted by the high participation of the TGG disulfide bridges conformation that is characteristic for non-gluten dough matrices. This effect could explain the indirect participation of the S-S bridges conformation in the low viscoelastic behavior of gluten-free doughs. By analyzing analogous relationships, Nawrocka et al. [2015] formulated similar suggestions as obtained in our work, where the increase in the number of TGG and TGT conformations and a decrease in GGG conformation promoted the aggregation and folding of gluten proteins.

The effects of the structural aspect of non-gluten proteins on the pasting properties of GF doughs are presented in Figure 7B and Table 5. PCA analysis showed a high positive correlation between GT and $\beta$-sheet $(\mathrm{r}=0.913)$ and $\alpha$-helix $(r=0.940)$ values, and a negative relation with $A \beta$-sheet $(\mathrm{r}=-0.882)$ content. PV value was also negatively correlated with the tryptophan content as indicated by $\mathrm{I}\left(760 \mathrm{~cm}^{-1}\right)$ standards. This indicates that the PV value may be affected by the degree of buriedness of tryptophan residues. However, the BD parameter was positively correlated with 
TABLE 5. Correlation matrix (Pearsons' coefficients r) between mixing parameter, pasting properties, viscoelastic characteristics and structure fractions of proteins of the tested doughs.

\begin{tabular}{|c|c|c|c|c|c|c|c|c|c|c|c|c|c|c|c|c|c|c|c|c|}
\hline Variables & WA & $G^{\prime}$ & G” & $\tan \delta$ & GT & IV & PV & FV & $\mathrm{BD}$ & SB & AGR & $\mathrm{P} \beta$-sh & $\beta$-sh & $\alpha-h x$ & $\beta$-trn & $\mathrm{A} \beta$-sh & GGG & TGG & TGT & $\mathrm{R}$ \\
\hline$G^{\prime}$ & -0.173 & & & & & & & & & & & & & & & & & & & \\
\hline G” & -0.676 & 0.559 & & & & & & & & & & & & & & & & & & \\
\hline $\tan \delta$ & -0.444 & -0.658 & 0.228 & & & & & & & & & & & & & & & & & \\
\hline GT & 0.375 & 0.333 & -0.545 & -0.875 & & & & & & & & & & & & & & & & \\
\hline IV & -0.122 & -0.288 & -0.568 & -0.030 & 0.458 & & & & & & & & & & & & & & & \\
\hline PV & 0.646 & -0.403 & -0.828 & -0.151 & 0.367 & 0.594 & & & & & & & & & & & & & & \\
\hline FV & 0.806 & -0.178 & -0.795 & -0.417 & 0.518 & 0.416 & 0.947 & & & & & & & & & & & & & \\
\hline $\mathrm{BD}$ & 0.190 & -0.618 & -0.679 & 0.269 & 0.096 & 0.804 & 0.848 & 0.637 & & & & & & & & & & & & \\
\hline SB & 0.749 & -0.227 & -0.816 & -0.364 & 0.510 & 0.504 & 0.973 & 0.994 & 0.711 & & & & & & & & & & & \\
\hline AGR & 0.846 & 0.346 & -0.451 & -0.817 & 0.651 & -0.085 & 0.508 & 0.757 & -0.016 & 0.691 & & & & & & & & & & \\
\hline $\mathrm{P} \beta$-sh & -0.283 & -0.712 & 0.037 & 0.947 & -0.780 & 0.155 & 0.154 & -0.126 & 0.530 & -0.066 & -0.658 & & & & & & & & & \\
\hline$\beta$-sh & 0.351 & 0.662 & -0.242 & -0.983 & 0.913 & 0.187 & 0.203 & 0.434 & -0.159 & 0.398 & 0.759 & -0.905 & & & & & & & & \\
\hline$\alpha$-hx & 0.536 & 0.194 & -0.692 & -0.794 & 0.940 & 0.558 & 0.652 & 0.769 & 0.359 & 0.767 & 0.744 & -0.600 & 0.844 & & & & & & & \\
\hline$\beta-\operatorname{trn}$ & -0.681 & -0.394 & 0.487 & $\mathbf{0 . 8 3 7}$ & -0.772 & -0.235 & -0.625 & -0.819 & -0.195 & -0.783 & -0.930 & 0.621 & $-\mathbf{0 . 8 4 7}$ & -0.888 & & & & & & \\
\hline $\mathrm{A} \beta$-sh & -0.721 & -0.300 & 0.611 & 0.885 & -0.882 & -0.251 & -0.580 & -0.782 & -0.146 & -0.745 & -0.922 & 0.714 & -0.879 & -0.940 & 0.958 & & & & & \\
\hline GGG & -0.687 & -0.449 & -0.021 & 0.516 & -0.133 & 0.526 & -0.219 & -0.470 & 0.269 & -0.383 & -0.813 & 0.413 & -0.419 & -0.248 & 0.650 & 0.534 & & & & \\
\hline TGG & 0.693 & 0.545 & -0.122 & -0.728 & 0.423 & -0.275 & 0.347 & 0.608 & -0.158 & 0.532 & 0.924 & -0.582 & 0.670 & 0.529 & -0.852 & -0.751 & -0.946 & & & \\
\hline TGT & 0.485 & 0.154 & 0.268 & 0.002 & -0.416 & -0.823 & -0.068 & 0.097 & -0.390 & 0.012 & 0.389 & 0.000 & -0.141 & -0.318 & -0.112 & -0.002 & -0.818 & 0.587 & & \\
\hline $\mathrm{R}$ & 0.221 & -0.554 & -0.563 & 0.314 & -0.039 & 0.676 & 0.851 & 0.653 & 0.970 & 0.717 & 0.022 & 0.596 & -0.215 & 0.267 & -0.213 & -0.102 & 0.106 & -0.040 & -0.193 & \\
\hline I & -0.499 & 0.497 & 0.602 & -0.186 & 0.028 & -0.452 & -0.914 & -0.798 & -0.865 & -0.829 & -0.280 & -0.484 & 0.136 & -0.310 & 0.377 & 0.255 & 0.211 & -0.235 & -0.111 & -0.940 \\
\hline
\end{tabular}

WA - water absorption, G' - storage modulus; G" - loss modulus; $\tan \delta$ - loss tangent, GT - gelatinization temperature, IV - initial viscosity, PV - peak viscosity, FV - final viscosity, BD - breakdown, SB - setback, AGR - aggregates, P $\beta$-sh - pseudo $\beta$-sheet, $\beta$-sh - $\beta$-sheet, $\alpha$-hx - $\alpha$-helix, $\beta$-trn - $\beta$-turn, $\mathrm{A} \beta$-sh - antiparallel $\beta$-sheet, GGG - gauche-gauche-gauche, TGG - trans-gauche-gauche, TGT - trans-gauche-trans, R - ratio of the doublet intensity of tyrosine, I - spectrum intensity characteristic of the tryptophan band. In bold: very strong correlations $r \geq 0.8$; in Italics: strong correlations $r \geq 0.7$.

the $\mathrm{R}$ ratio $(\mathrm{r}=0.970)$, indicating the effect of tyrosyl residues on the swelling capacity of starch granules during heating and the distribution of starch granules in the protein matrix. This relationship suggests that if more tyrosyl residues are exposed, the swelling capacity of starch granules increases.

\section{CONCLUSIONS}

This study contributed to understanding the development mechanism of gluten-free GF doughs by examining protein structural features. The solid behavior that characterized GF dough was due to the absence of $\mathrm{P} \beta$-sheet secondary structure. We demonstrated that the protein network of gluten-free MFB dough matrix was principally developed by the production of $\beta$-sheet and $\alpha$-helix structures. At the same time, a decrease of $\beta$-turn and $A \beta$-sheet secondary structures was observed, greatly affecting the viscoelastic behaviour of the examined doughs. PCA also showed that the water absorption of the starch granules increased when more tyrosyl residues were exposed. Moreover, we noted that the TGG disulfide bridge conformation strongly participated in GF protein network development and promoted the high structuralization that contributed to the low bread-making quality of GF components. In addition, strong correlations were observed between pasting properties and structural composition of the tested GF doughs as compared to gluten SW dough. Finally, an improved IMFB formula with the addition of a fraction of hydrothermally-treated maize flour showed relatively good structural properties as compared to other doughs tested.

\section{CONFLICT OF INTEREST}

Authors declare no conflict of interest.

\section{ORCID IDs}

A. Nawrocka https://orcid.org/0000-0001-8618-2092

A. Sujak https://orcid.org/0000-0001-5616-3827

M. Szymańska-Chargot https://orcid.org/0000-0002-2251-4307

M. Tomczyńska-Mleko https://orcid.org/0000-0002-6870-1060

A. Wójtowicz https://orcid.org/0000-0001-5981-6109 


\section{REFERENCES}

1. AACC. (1995). Approved Method of the AACC. 9th Edition, American Association of Cereal Chemists, St. Paul, USA.

2. AOAC. (2000). Official Methods of Analysis. 17th Edition, The Association of Official Analytical Chemists, Gaithersburg, USA.

3. Barak, S., Deepak, M., Khatkar, B.S. (2014). Influence of gliadin and glutenin fractions on rheological, pasting, and textural properties of dough. International Journal of Food Properties, 17(7), $1428-1438$.

https://doi.org/10.1080/10942912.2012.717154

4. Belton, P.S. (1999). Mini review: On the elasticity of wheat gluten. Journal of Cereal Science, 29(2), 103-107. https://doi.org/10.1006/jcrs.1998.0227

5. Benatallah, L., Zidoune, M.N.,Michon, C. (2012). Optimization of HPMC and water addition for a gluten-free formula with rice and field bean based on rheological properties of doughs. International Review of Chemical Engineering, 4(5), 1755-2035.

https://doi.org/10.3390/foods8050156

6. Bourekoua, H., Benatallah, L., Zidoune, M.N., Rosell, C.M. (2016). Developing gluten free bakery improvers by hydrothermal treatment of rice and corn flours. LWT - Food Science and Technology, 73, 342-350.

https://doi.org/10.1016/j.Iwt.2016.06.032

7. Dib, A., Wójtowicz, A., Benatallah, L., Bouasla, A., Zidoune, M.N. (2018). Effect of hydrothermal treated corn flour addition on the quality of corn-field bean gluten-free pasta. Contemporary Research Trends in Agricultural Engineering 10, 1-9. https://doi.org/10.1051/bioconf/20181002003

8. Dus, S.J., Kokini, J.L. (1990). Prediction of the nonlinear viscoelastic properties of hard wheat flour dough using the Bird-Carreau constitutive model. Journal of Rheology, 34(7), 1069-1084. http://dx.doi.org/10.1122/1.550110

9. Ferrer, E.G., Gómez, E.G., Anon, M.C., Puppo, M.C. (2011). Structural changes in gluten protein structure after addition of emulsifier. A Raman spectroscopy study. Spectrochimica Acta, A79(1), 278-281.

https://doi.org/10.1016/j.saa.2011.02.022

10. Fetouhi, A., Benatallah, L., Nawrocka, A., Szymańska-Chargot, M., Bouasla, A., Tomczyńska-Mleko, M., Zidoune, M.N., Sujak, A. (2019). Investigation of viscoelastic behaviour of rice-field bean gluten free dough using the biophysical characterization of proteins and starch: a FT-IR study. Journal of Food Science and Technology, 56(3), 1316-1327.

https://doi.org/10.1007/s13197-019-03602-2

11. Gómez, A.V., Ferrer, E.G., Añón, M.C., Puppo, M.C. (2013). Changes in secondary structure of gluten proteins due to emulsifiers. Journal of Molecular Structure, 1033, 51-58. https://doi.org/10.1016/j.molstruc.2012.08.031

12. He, H., Hoseney, R.C. (1992). Factor controlling gas retention in non-heated doughs. Cereal Chemistry, 69(1), 1-6.

13. Herrero, A.M. (2008). Raman spectroscopy for monitoring protein structure in muscle food systems. Critical Reviews in Food Science and Nutrition, 48(6), 512-523.

https://doi.org/10.1080/10408390701537385
14. Hřivna, L., Zigmundová, V., Burešowá, I., Maco, R., Vyhnánek, T., Trojan, V. (2018). Rheological properties of dough and baking quality of products using coloured wheat. Plant, Soil and Environment, 64, 203-208.

https://doi.org/10.17221/62/2018-PSE

15. Khatkar, B.S., Schofield, J.D. (2007). Dynamic rheology of wheat flour dough I. Non-linear viscoelastic behavior. Journal of the Science of Food and Agriculture, 82 (8), 827-829.

https://doi.org/10.1002/jsfa.1109

16. Larsson, H., Eliasson, A.C. (1997). Influence of the starch granule surface on the rheological behaviour of wheat flour dough. Journal of Texture Studies, 28(5), 487-501. https://doi.org/10.1111/j.1745-4603.1997.tb00132.x

17. Lazaridou, A., Duta, D., Papageorgiou, M., Belc, N., Biliaderis, C.G. (2007). Effects of hydrocolloids on dough rheology and bread quality parameters in gluten-free formulations. Journal of Food Engineering, 79(3), 1033-1047.

https://doi.org/10.1016/j.jfoodeng.2006.03.032

18. Linlaud, N., Ferrer, E., Puppo, M.C., Ferrero, C. (2011). Hydrocolloid interaction with water, protein, and starch in wheat dough. Journal of Agricultural and Food Chemistry, 59(2), 713-719. https://doi.org/10.1021/jf1026197

19. Matsushima, N., Danno, G-I., Takazewa, I., Izumi, Y. (1997). Three-dimensional structure of maize $\alpha$-zein proteins studied by small-angle X-ray scattering. Biochimica et Biophysica Acta (BBA) - Protein Structure and Molecular Enzymology, 1339(1), $14-22$.

https://doi.org/10.1016/S0167-4838(96)00212-9

20. Mejia, C.D., Mauer, L.J., Hamaker, B.R. (2007). Similarities and differences in secondary structure of viscoelastic polymers of maize a-zein and wheat gluten proteins. Journal of Cereal Science, 45(3), 353-359.

https://doi.org/10.1021/jf203073a

21. Nawrocka, A., Szymańska-Chargot, M., Miś, A., Ptaszyńska, A.A., Kowalski, R., Waśko, P., Gruszecki, W.I. (2015). Influence of dietary fibre on gluten proteins structure - a study on model flour with application of FT-Raman spectroscopy. Journal of Raman Spectroscopy, 46(3), 309-316. https://doi.org/10.1002/jrs.4648

22. Nawrocka, A., Szymańska-Chargot, M., Miś, A., Wilczewska, A.Z., Markiewicz, K.H. (2016a). Dietary fiber-induced changes in the structure and thermal properties of gluten proteins studied by Fourier Transform-Raman spectroscopy and thermogravimetry. Journal of Agriculture and Food Chemistry, 64(10), 2094-2104. https://doi.org/10.1021/acs.jafc.5b05712

23. Nawrocka, A., Miś, A., Szymańska-Chargot, M. (2016b). Characteristics of relationships between structure of gluten proteins and dough rheology: influence of dietary fibres studied by FT Raman spectroscopy. Food Biophysics, 11(1), 81-90. https://doi.org/10.1007/s11483-015-9419-y

24. Overman, S.A., Aubrey, K., Vispo, N.S., Cesareni, G., Thomas Jr, G. (1994). Novel tyrosine markers in Raman spectra of wild-type and mutant (Y21M and Y24M) Ff virions indicate unusual environments for coat protein phenoxyls. Biochemistry, 33, 1037-1042.

https://doi.org/10.1021/bi00171a001 
25. Pelton, J.T., McLean, L.R. (2000). Spectroscopic methods for analysis of protein secondary structure. Analytical Biochemistry, 277(2), 167-176.

https://doi.org/10.1006/abio.1999.4320

26. Pourfarzad, A., Habibi Najafi, M.B., Haddad Khodaparast, M.H., Hassanzadeh Khayyat, M. (2015). Serish inulin and wheat biopolymers interactions in model systems as a basis for understanding the impact of inulin on bread properties: a FTIR investigation. Journal of Food Science and Technology, 52(12), 7964-7973. https://doi.org/10.1007/s13197-015-1939-4

27. Ragaee, S., Abdel-Aal, E.M. (2006). Pasting properties of starch and protein in selected cereals and quality of their food products. Food Chemistry, 95(1), 9-18.

https://doi.org/10.1016/j.foodchem.2004.12.012

28. Rygula, A., Majzner, K., Marzec, K.M., Kaczor, A., Pilarczyk, M., Baranska, M. (2013). Raman spectroscopy of proteins: a review. Journal of Raman Spectroscopy, 44(8), 1061-1076. https://doi.org/10.1002/jrs.4335

29. Singh, H., MacRitchie, F. (2001). Application of polymer science to properties of gluten. Journal of Cereal Science, 33(3), 231-243. https://doi.org/10.1006/jcrs.2000.0360

30. Sivam, A.S., Sun-Waterhouse, D., Perera, C.O., Waterhouse, G.I.N. (2013). Application of FT-IR and Raman spectroscopy for the study of biopolymers in breads fortified with fiber and polyphenols. Food Research International, 50(2), 574-585. https://doi.org/10.1016/j.foodres.2011.03.039
31. Sivaramakrishnan, H.P., Senge, B., Chattopadhyay, P.K. (2004). Rheological properties of rice dough for making rice bread. Journal of Food Engineering, 62(1), 37-45. https://doi.org/10.1016/S0260-8774(03)00169-9

32. Tunick, M.H. (2011). Small-strain dynamic rheology of food protein networks. Journal of Agricultural and Food Chemistry, 59(5), 1481-1486.

https://doi.org/10.1021/jf1016237

33. Wang, K., Sun, D-W., Pu, H., Wei, Q. (2017). Principles and applications of spectroscopic techniques for evaluating food protein conformational changes: A review. Trends in Food Science \& Technology, 67, 207-219. https://doi.org/10.1016/j.tifs.2017.06.015

34. Wang, Q., Li, Y., Sun, F., Li, X., Wang, P., Sun, J., Zeng, J., Wang, C., Hu, W., Chang, J., Chen, M., Wang, Y., Li, K., Yang, G., He, G. (2015). Tannins improve dough mixing properties through affecting physicochemical and structural properties of wheat gluten proteins. Food Research International, 69, 64-71.

https://doi.org/10.3390/ijms161226132

35. Wieser, H. (2007). Chemistry of gluten proteins. Food Microbiology, 24(2), 115-119.

https://doi.org/10.1016/j.fm.2006.07.004

36. Zavareze, E.M., Guerra Dias, A.R. (2011). Impact of heat-moisture treatment and annealing in starches: A review. Carbohydrate Polymers, 83(2), 317-328.

https://doi.org/10.1016/j.carbpol.2010.08.064 